\title{
La política neoliberal, sus repercusiones \\ y su relación con la comunicación familiar \\ en el desarrollo académico en Michoacán
}

Luz Zareth Moreno Basurto ${ }^{1}$

https://doi.org/10.36105/stx.2018n1.10

\section{Resumen}

El artículo tiene por objetivo analizar las implicaciones de la política neoliberal de México en lo económico y lo sociocultural. Específicamente se consideran tres aspectos coyunturales de la economía política tributaria y dependiente: a) tratados de libre comercio, inversión y fiscales; b) reducción del poder fiscal, de las instituciones, las facultades y las funciones del Estado, y c) reducción del poder adquisitivo del salario y del mercado interno. A partir de ello y como parte de una investigación exploratoria, se encontró que en Michoacán, de 2010 a 2015, se han incrementado en 3.8\% las jefaturas familiares femeninas. Una de las causas es la migración masculina hacia Estados Unidos. La situación económica y política del país ha permitido la reestruccturación del seno familiar. La comunicación entre sus integrantes se ha visto mermada, sus procesos de interacción han cambiado y en consecuencia el rendimiento y desarrollo académico de los niños ha disminuido.

\section{Palabras clave}

Neoliberalismo, comunicación, familia, interacción, desarrollo académico, tratado de libre comercio.

\footnotetext{
1 Doctoranda del programa de Investigación de la Comunicación en la Universidad Anáhuac México. luzzareth@yahoo.com.mx
} 


\section{Introducción}

México es un país que se encuentra sumergido en múltiples crisis; la más fuerte sin lugar a dudas en este 2016 es la económica. Muestra de ello es el panorama tan oscuro que se observa a partir de la caída del peso y de la problemática que vive el sector energético, lo cual ha provocado (si no es que lo hará) inflación, distorsión en los flujos de exportación, aumento en el costo de financiamiento para las empresas, entre otros.

Esta situación, si bien responde a cuestiones globales de las economías, también es producto de los intereses políticos y económicos de quienes ocupan cargos estratégicos en el país. En aras de ganar poder, los dirigentes y los gobernantes han sacrificado a los ciudadanos haciéndolos padecer pobreza y niveles de vida poco satisfactorios. Las familias, sobre todo las de clase media, media baja y baja, son las que reciben un impacto negativo mayor.

Desde 2014 el horizonte para el país en cuanto a su situación económica no era muy alentador. Ya entonces el gobernador del Banco de México (Banxico), Agustín Carstens, explicaba lo golpeada que estaba la economía: "hemos observado que hemos sido afectados por choques reales externos, el precio de petróleo, la menor demanda de bienes y servicios a nivel mundial y la previsión de que las tasas en Estados Unidos (EU) suban” (Forbes, 2015). Evidentemente, Carstens lo atribuía a factores externos, los cuales, si bien han influido en esta situación que se presenta mundialmente, no son determinantes. Mucho de lo que hoy se vive, como ya se señaló, responde a las decisiones, políticas, iniciativas, tratados y acuerdos que ha instaurado el gobierno mexicano.

Con base en lo anterior, el objetivo de este artículo es analizar algunos aspectos coyunturales de México y su relación con la dinámica familiar de Michoacán respecto a la comunicación padres e hijos en torno al desarrollo académico. La tesis que se sostiene es que la política neoliberal de México no sólo ha repercutido negativamente en aspectos económicos y socioculturales, sino que también ha permeado las relaciones comunicativas familiares asociadas al desarrollo académico de los hijos.

La estructura del trabajo parte de un breve preámbulo acerca del liberalismo, el liberalismo económico y el liberalismo político con la finalidad de que se pueda comprender el apartado posterior que versa sobre la política neoliberal en México. Enseguida, se describen tres limitantes para el crecimiento de la economía política, las cuales se retoman del texto Estrategia de reindustrialización acelerada de México de Alberto Montoya Martín del Campo (2015): a) tratados de libre comercio, inversión y fiscales; b) reducción del poder fiscal, las instituciones, facultades y funciones del Estado, y c) reducción del poder adquisitivo del salario y del mercado interno. Se continúa con un acercamiento a la manera en que algunos elementos coyunturales inciden en la familia, la comunicación y el desarrollo académico en 
el estado de Michoacán. Por último, se hace una relación entre lo macro (política neoliberal a nivel nacional) y lo micro (Michoacán) para concluir con una alternativa de solución.

\section{Liberalismo, liberalismo económico y liberalismo político}

La comprensión de la política neoliberal de México puede entenderse a la luz del liberalismo como defensor de las iniciativas individuales, pues busca limitar la intervención del Estado en la vida económica, social y cultural de los países. Aunque tradicionalmente se ha afirmado que la doctrina liberal tiene su origen en el pensamiento de la Escuela Escocesa del siglo XVIII, o en el ideario de la Revolución Francesa, lo cierto es que puede remontarse hasta la tradición clásica del pensamiento filosófico griego y de la ciencia jurídica romana (Huerta, 2014).

Así, el liberalismo es una corriente de pensamiento filosófico-económico que busca limitar al máximo el poder del Estado sobre los seres humanos y la sociedad civil. En este sentido, forman parte del ideario liberal

la defensa de la economía de mercado (también denominada "sistema capitalista" o de "libre empresa"); la libertad de comercio, la libre circulación de personas, capitales y bienes; el mantenimiento de un sistema monetario rígido que impida su manipulación inflacionaria por parte de los gobernantes; el establecimiento de un Estado de Derecho [...] la limitación y control del gasto público, el principio del presupuesto equilibrado y el mantenimiento de un nivel reducido de impuestos [...] la utilización de procedimientos democráticos para elegir a los gobernantes, y el establecimiento, en suma, de un orden mundial basado en la paz y en el libre comercio voluntario, entre todas las naciones de la tierra (Huerta, 2014, párr. 1).

La definición sirve para acotar y caracterizar al liberalismo de manera muy sucinta, pues ya Bobbio y Matteucci (1982) señalaban que ni los historiadores ni los politólogos se ponen de acuerdo en estipular una definición común de liberalismo debido a que está ligada a la historia de la democracia, por lo cual "es difícil encontrar un consenso sobre lo que hay de liberalismo y lo que hay de democrático en las actuales democracias liberales” (Bobbio \& Matteucci, 1982, p. 905). Además, el liberalismo se presenta en los diferentes países en tiempos históricos diversos, por lo cual resulta complicado encontrar "en el plano sincrónico el elemento liberal que unifica diversas historias” (Bobbio y Matteucci, 1982, p. 905).

Es importante comentar que, desde el punto de vista filosófico, el liberalismo "exalta la unidad de la voluntad política soberana” (Bobbio \& Matteucci, 1982, p. 918), mientras 
que desde la perspectiva política "defiende las diferencias entre los diversos grupos sociales” (Bobbio \& Matteucci, 1982, p. 918). Con estas distinciones se entiende la variedad de concepciones y postulados teóricos que se han suscitado en torno al tema. Algunos lo hacen desde la filosofía, otros se orientan a la política y algunos más se acercan al concepto desde la economía o incluso desde la historia.

Ahora bien, en cuanto al liberalismo económico se refiere, uno de los principales precursores de esta concepción teórica es Adam Smith, quien con su libro La riqueza de las naciones, de 1776, propone la idea de que la armonía entre el interés particular y el general será la fuente de la riqueza del Estado, pues creía que "cuando uno trabaja para sí mismo sirve a la sociedad con más eficacia que si trabaja para el interés social” (Historia y biografías, 2014). De esta manera, lo que hace Smith es enfatizar que el mercado se regulará por libre concurrencia, que el trabajador elegirá libremente su trabajo, que la mano de obra se desplazará libremente y que el contrato de trabajo será un acuerdo libre entre patronos y obreros, es decir, la libertad en su más amplia expresión (laissez faire). Por último, cabe resaltar los tres principios fundamentales del liberalismo económico: libertad personal, propiedad privada e iniciativa y control individual de la empresa (Ferguson, 1980).

Finalmente, y de manera muy general, el liberalismo político, como oposición al absolutismo, es una doctrina que defiende la libertad individual y la iniciativa privada. Asimismo, confiere igualdad a los ciudadanos ante la ley; valora al individuo como persona única y en ejercicio de su plena libertad, por encima de los aspectos colectivos; concede el derecho a la propiedad privada como fuente de desarrollo e iniciativa individual y permite la elección de los representantes públicos en un entorno democrático a través del voto.

Particularmente, desde el punto de vista de John Rawls, en su texto Liberalismo político, de 1980, los ciudadanos se relacionan entre sí a partir de un pacto social y mediante la existencia de una mano invisible es que se logra un equilibrio/estabilidad en el que se superan las desigualdades de los más débiles o desfavorecidos. En este punto el Estado tiene como objetivo atender a las instituciones sociales sin alterar las actividades de la economía y las libertades individuales. La política, desde esta óptica

se ocupa de asuntos de la más profunda importancia para el universo de la vida humana: el alcance y la naturaleza de la libertad personal, la disponibilidad de oportunidades y de beneficios económicos, las bases sociales del autorrespeto y, en general, de los bienes indispensables para llevar una vida satisfactoria por propia cuenta. Siendo este el caso, la concepción política requiere emplear tanto una idea de la persona, en términos que permitan darle sentido a la importancia y el propósito de tales bienes, como una idea de los propios bienes que la política se encargará de distribuir. Sobre este punto, Rawls invoca la idea de una "concepción política de la persona" que caracteriza con 
dos “poderes morales": la capacidad de tener un sentido de justicia y la capacidad para adoptar una concepción del bien (Nusbaum, 2014, párr. 7).

Con base en lo descrito hasta ahora, el liberalismo en América Latina está ligado al "periodo preindependentista como aroma ideológico justificatorio de la necesidad de romper el vínculo colonial" (Bobbio \& Matteucci, 1982, p. 931). En México, su adopción data del siglo XVI aproximadamente, donde la formación social mexicana es expresión de cómo se va desarrollando la acumulación capitalista (Rionda, s. f.), esto a partir de acciones como el surgimiento de capitales mineros que se alejan de ser de tipo estamental para convertirse a una abierta relación salarial; el surgimiento de una burocracia urbana criolla y peninsular que mantienen intereses liados al capital incipiente que, no obstante, inicia su penetración en la vida económica colonial como parte de la formación de capitales autónomos; la imposición de los mestizos, quienes ven en la libertad de la mano de obra la oportunidad de participar como trabajadores en la economía novohispana y la sustitución del jornal por el salario en regiones mineras, entre otros; en el país comienzan a ganar terreno los ideales del liberalismo (Rionda, s. f.).

Desde entonces y a la fecha, México se ha visto afectado no sólo en el plano económico por los cambios que representa el liberalismo en sus distintas facetas. En recientes fechas el neoliberalismo también ha incidido de manera importante a nivel estructural en reformas vitales para el país, así como en aspectos relativos a la política, economía, cultura y sociedad. A continuación se tratarán de explicar algunos de estos resultados, no sin antes hacer hincapié en que el objetivo del trabajo no es desde luego hacer un análisis exhaustivo de lo que es el liberalismo ni el neoliberalismo. Baste tenerlos como referentes de lo que hoy en día enmarca o condiciona de alguna manera lo que es México y los mexicanos.

Para concluir este apartado, y de vuelta al liberalismo, queda señalar que en materia liberal existen dos orientaciones: "la doctrinaria de José María Luis Mora y la pragmática de Lucas Alamán y Estevan de Antuñano. Parten de tesis liberales con fuerte fundamento fisiocrático puesto que consideran que la economía nacional es básicamente primaria" (Rionda, s. f., párr. 15).

\section{Política neoliberal de México (lo macro)}

El neoliberalismo es una corriente político-económica que promueve la intervención del Estado al mínimo. Se refiere a la política económica con énfasis tecnocrático y macro-económico que pretende reducir al mínimo la intervención estatal tanto en materia económica 
como social. Se defiende, por tanto, el libre mercado capitalista como mejor garante del equilibrio institucional y el crecimiento económico de un país.

En México esta concepción de política neoliberal emerge como muestra de que la liberalización del mercado de capitales y de los mercados financieros no necesariamente conlleva a índices más altos de crecimiento, así como tampoco lo hacen la privatización de empresas públicas ni la minimización de las condiciones a la entrada de inversión extranjera directa (transnacionales). Baste observar las crisis de México en 1994, la de Brasil en 1999 y la de Argentina en 2001 para constatar los defectos en este tipo de políticas (Stiglitz, 2007) que contrastan con los resultados de ciudades como Macao, Izmir, Bursa o Xiamen que, sin ser los lugares más conocidos del planeta, se encuentran entre los diez que más crecieron en 2014, de acuerdo con el Centro de Investigaciones Estadounidense Brookings Institute que ubica a cinco de los 10 con más crecimiento económico en China, cuatro en Turquía y uno en Dubai (Justo, 2015).

En el país esta política económica data de la década de los ochenta, con el Consenso de Washington, y sigue inamovible pese a sus efectos negativos, ya que los principales partidos políticos, ligados a los grupos empresariales beneficiarios de las privatizaciones, garantizan larga vida al neoliberalismo (Romero, 2015). Desde entonces,

lo que estamos viviendo es una tendencia a la concentración extrema de la riqueza, que provoca que tengamos un puñado de multimillonarios (entre ellos el más rico del mundo) al mismo tiempo y en contraste con la enorme cantidad de población en pobreza extrema (Garduño, s. f., citado por Romero, 2015, párr. 8).

Ciertamente, y como se percibe en el día a día de los mexicanos, la situación es sumamente desfavorable para quien gana el salario mínimo o para quien no se encuentra dentro de los grupos de poder, y muy lejos queda lo que en teoría establecía Adam Smith respecto a la idea de que en la búsqueda del beneficio propio se lograría el de los demás (Montoya, 2015).

Tremendo error el pensar que los hombres no se corromperían y que la intervención mínima del Estado sería suficiente. En la realidad se puede corroborar cómo el ser humano se ha desprendido de sí mismo como ser social comprometido con sus semejantes y se ha transformado en un ser individualista, que solo busca la satisfacción personal. Lejos ha quedado la noción aristotélica de comunidad nacional equivalente a una comunidad ética, cuyo ejercicio reflexivo daría pie a la humanización de todas las personas, se alcanzarían mayores grados de humanidad y de civilización, a través del equilibrio de las bases de tipo racional y de tipo técnico (Montoya, Olvera, Brito \& Lara, 2010). 
Con todo, mediante el neoliberalismo México logró insertarse en la economía mundial a través de la incorporación al Acuerdo General sobre Aranceles Aduaneros y Comercio (GATT) y después al Tratado de Libre Comercio (TLC) con Estados Unidos y Canadá, entre otros. Estos hechos se vendieron a los mexicanos como situaciones que generarían grandes beneficios económicos. Sin embargo, no ha sido así, la mayoría de los bolsillos de las familias en México muestran lo contrario. En palabras de José Luis Calva Téllez, miembro del Instituto de Investigaciones Jurídicas de la Universidad Nacional Autónoma de México (UNAM) "el poder adquisitivo de los salarios cayó 71.5 por ciento y los salarios manufactureros perdieron el 38.5 por ciento de su poder de compra” (Calva, s. f., citado por Romero, 2015, párr. 3).

Así, lo que se percibe diariamente dista mucho de lo que se dice a nivel discursivo en los medios de comunicación masiva por los líderes políticos. La verdad es que las ventajas pertenecen a unos cuantos. Baste como ejemplo la reforma fiscal para bajar las tasas, incluso de la renta, para particulares de altos ingresos y empresas, donde se amplió la base de contribuyentes y se afectó a los más vulnerables.

La evidencia no deja lugar a dudas y es que el neoliberalismo en México sirve a los poderosos, a los que tienen más, pero sobre todo y en primera instancia a las potencias globales, entre ellas EE. UU., con quien se ha establecido en últimas fechas una relación de cercanía que no es gratuita. Sírvase observar publicaciones tales como Building a North American Community. Report of the Independent Task Force on the Future of North America del Council on Foreign Relations, Canadian Council of Chief Executives y el Consejo Mexicano de Asuntos Internacionales del 2005; el Council on Forign Relations (CFR): La cara oculta del poder globalizado, de Salbuchi 2003; North America.Time for a New Focus, de Petraeus, Zoellick, O'Neil y Shannon del 2014 y Oil, Mexico and the transboundary agreemente. A minority staff report prepared for the use of the committe on foreign relations United States Senate One bundred twelfth Congress, second sesion, del Committee on Foreign Relations en 2012. En éstas se puede corroborar el interés de EE. UU. por colonizar a México a través de diferentes mecanismos, para así garantizar su seguridad energética y su estabilidad económica.

Un ejemplo claro es la Reforma Energética que, lejos de beneficiar a México y a los mexicanos, es conveniente, en todo caso, para EE. UU. ¿Algunas razones? Dice Montoya (2014) que cuando se aceptó dicha reforma, se vulneró grave e irreversiblemente la soberanía nacional y el pacto constitucional de los mexicanos, porque se realizó en función de los intereses económicos de corporaciones globales y potencias extranjeras y porque su único propósito fue contribuir a la seguridad energética estadounidense. Algunos de los argumentos que respaldan esto se pueden observar en los cambios mismos que sufrió la Constitución en materia energética, entre otros: 
a) Se eliminó la facultad exclusiva de la Nación de llevar a cabo la explotación del petróleo y de los carburos de hidrógeno sólidos, líquidos o gaseosos.

b) Se suprimió a la Nación como el sujeto que realiza la explotación exclusiva del petróleo y de los carburos de hidrógeno sólidos, líquidos o gaseosos, y se la sustituiye por lo que determine la ley reglamentaria del artículo 27 constitucional.

c) Se eliminó la facultad exclusiva de la Nación de generar, conducir, transformar, distribuir y abastecer energía eléctrica que tenga por objeto la prestación de servicio público.

d) Se redujeron las facultades del Estado en electricidad, al control del sistema eléctrico nacional, así como el servicio público de transmisión y distribución de energía eléctrica.

e) El Estado mexicano perdió propiedad, dominio directo, el derecho de explotación exclusiva e integral de los hidrocarburos; $y$ en materia de electricidad, se convierte en un ente técnico para el despacho de la energía eléctrica, misma que será generada y abastecida por corporaciones extranjeras (Montoya, 2014).

El servilismo de la clase política hacia EE. UU. es más que obvio; lamentablemente muchos mexicanos siguen creyendo que el país se beneficiará con las decisiones tomadas por el gobierno y en verdad piensan que con la reforma energética se tendrá combustible a precios más bajos y competitivos. Desgraciadamente la realidad es otra; baste observar el interés de potenciales participantes (Chevron, Exxon, Maersk, Marathon Oil, etc.), la nula participación de Petróleos Mexicanos (Pemex) en la primera fase de licitación (ronda 1: 109 áreas de exploración y 60 de producción), así como el precio del petróleo, cuyo promedio anual en lo que va del 2016 es de $\$ 86.001$, el cual va a la baja comparado con otros periodos: de 2013 a 2014 se mantuvo en $\$ 98.436$, mientras que de 2011 a 2012 osciló entre \$101.130 a $\$ 101.960$ (Secretaría de Economía, 2016).

Las acciones de la Secretaría de Hacienda y Crédito Público (SHCP) y Banxico: ajuste preventivo al gasto público por 132.3 mil millones de pesos, que encierra a la Comisión Federal de Electricidad (CFE), y un recorte al presupuesto del presente ejercicio fiscal de Pemex; la elevación a 3.75\% de la tasa de interés de referencia y la suspensión de los mecanismos de venta de dólares (Excélsior, 2016) no han podido hacer que la situación mejore y el panorama, mientras tanto, sigue siendo pesimista para los mexicanos porque hay una crisis recurrente en la economía nacional, porque el crecimiento sostenido no ha podido lograrse y porque se padecen constantes inflaciones, desempleo, inseguridad, pobreza, etcétera. 


\section{Limitantes para el crecimiento de la economía política de México}

Como se expresó con anterioridad, el problema general de México es su política neoliberal, porque ha frenado el crecimiento y desarrollo económico. No obstante, es importante efectuar una explicación más detallada de al menos tres factores que se consideran relevantes en esta inmersión en que se encuentra el país: los tratados de libre comercio, de inversión y fiscales; la reducción del poder fiscal, las instituciones, facultades y funciones del Estado y, por último, la reducción del poder adquisitivo del salario y del mercado interno.

\section{a) Tratados de libre comercio, inversión y fiscales}

El primer factor que se analizará con detenimiento es el referente a los tratados de libre comercio, inversión y fiscales. Esto obedece a las imposiciones y restricciones que adopta la democracia mexicana al favorecer la acumulación de las corporaciones globales y al situar los objetivos de desarrollo de otras naciones por encima de los fines de desarrollo humano, social, cultural, político y económico de México como Estado nación.

De esta manera se tiene que los tratados limitan las acciones de fomento, compensación y protección del aparato productivo nacional. Una muestra de ello lo representa el Tratado de Libre Comercio de América del Norte (TLCAN), ya que prevalece en él una asimetría jurídica, en virtud de que para México es ley suprema, de carácter autoejecutivo, mientras que para los Estados Unidos de América sólo adquiere plena obligatoriedad en la medida en que su poder legislativo apruebe una legislación específica (Montoya, 2015). Así, el TLCAN se constituye más que como un acuerdo comercial como una política de Estado a largo plazo para la integración subordinada de México a los EE. UU.

Un aspecto más a considerar en este apartado se remite a que en el TLCAN no se incluyó la libre movilidad de la fuerza de trabajo ni un tratado migratorio relacionado con la dinámica de los mercados de trabajo de los tres países. Nuevamente los desequilibrios afloran, ya que la migración de personas extranjeras que vienen a trabajar a México sí está considerada bajo el concepto de "personas de negocios". Sin embargo, esto no aplica para los trabajadores mexicanos que desempeñan actividades agrícolas, industriales, de la construcción o de cualquier índole en Canadá o EE. UU.

El acuerdo laboral que exige el cumplimiento de las partes sobre la base de su legislación nacional, de velar por el ejercicio de los derechos de los trabajadores en los tres países no se ha cumplido en el caso de los trabajadores indocumentados mexicanos que han acudido al mercado laboral estadounidense (Montoya, 2015, p. 47). 
Los tratados de libre comercio, inversión y fiscales, por tanto, están hechos a la medida de Canadá y EE. UU., en el caso del TLCAN. México, más que obtener ganancias, pierde y no sólo en términos económicos, sino también en poder nacional y soberanía.

\section{b) Reducción del poder fiscal, las instituciones, facultades y funciones del Estado}

La segunda limitación estructural de la economía política nacional es la reducción significativa del poder fiscal, las instituciones, facultades y funciones del Estado, que conduce a la supresión, en la práctica, de su mandato de fomento económico y garante de la equidad y el desarrollo social (Montoya, 2015). Esto significa que las corporaciones globales, principalmente de inversión extranjera, tienen un poder equiparable al del Estado e incluso mayor, por lo que este último queda subordinado a los requerimientos y necesidades de dichas corporaciones.

Es así como se ha utilizado la renta petrolera para sustituir el vacío de recaudación de las corporaciones globales, lo que ha impedido su utilización para promover la inversión pública, social y privada nacional, pues la renta es capturada finalmente por las corporaciones globales por medio de las devoluciones de impuestos que oscilan anualmente entre 450,000 y 500,000 millones de pesos (Rodríguez, 2012, citado por Montoya, 2015).Este tipo de acciones no sólo son injustas, sino que operan en marcos de completa legalidad que son instaurados por el Estado, mismo que debería ver por el bienestar de los mexicanos y no al contrario.

La situación de reducción de poder fiscal se expresa en la concentración de los estratos más ricos de la población y en las corporaciones globales, por ende, se limita la inversión pública y los recursos del Estado para el desarrollo. La consecuencia inminente es que se elimina la inversión en los organismos públicos del Estado en todos los sectores (particularmente el energético) y se conduce a la

privatización del Estado nación a favor de las corporaciones globales, pues las inversiones e infraestructuras públicas pasan a ser objeto directo de negocio de éstas y se sustituyen los servicios públicos por concesiones gubernamentales de funciones públicas mediante contratos a largo plazo y con precios superiores para los consumidores (Montoya, 2015, p. 54).

Ante este hecho el Estado mexicano pierde su independencia y cede el poder a terceros que no deberían gozar de tantos beneficios. Lamentable que bajo criterios de este tipo los mexicanos estén perdiendo aquello que les pertenece por decreto, es decir, sus recursos naturales, entre ellos el petróleo. 


\section{c) Reducción del poder adquisitivo del salario y del mercado interno}

La reducción del mercado interno sofoca la dinámica del crecimiento económico debido a la disminución del poder adquisitivo del salario y de la proporción de los salarios en el Producto Interno Bruto (PIB), lo que a su vez limita la realización del círculo virtuoso inversión-empleo-consumo (Montoya, 2015).

El efecto es que se ha polarizado aún más la desigualdad en el ingreso y la riqueza. Tal como lo estipula el Consejo Nacional de Evaluación de la Política de Desarrollo Social (Coneval), el hecho de que los ingresos de las familias no hayan crecido en más de dos décadas no sólo implica una falta de desarrollo económico y social del país, sino también que la pobreza no se ha podido reducir a pesar del incremento de coberturas básicas de educación, salud y vivienda (Coneval, 2014). Así, nuevamente la realidad expresada en rostros de niños con hambre o de madres que viven en la calle se hace presente, pues siempre será insuficiente la ayuda que se pueda brindar mientras no se corrija lo que de fondo ha causado profundas heridas a México: la política neoliberal y la sed de poder de quienes gobiernan.

Un dato más que ayuda a tener una panorámica mayor es que entre 2005 y 2014 el ingreso laboral de las familias perdió poder adquisitivo respecto a la canasta alimentaria. Desde el 2007, el precio de los alimentos ha aumentado más que la inflación promedio, lo que implica de nueva cuenta que el poder adquisitivo ha caído más respecto a los alimentos que respecto a otros precios (Coneval, 2014). Ante este fenómeno, cómo se puede esperar que se cubra siquiera una de las necesidades básicas como la alimentación, si no alcanza. La pobreza se sigue incrementado y junto con ella otros males que dañan el tejido social, como la corrupción y la delincuencia. Sólo baste mirar que a nivel nacional el número de personas en situación de pobreza en 2010 fue de 52.8 millones, mientras que en 2012 fue de 53.3 millones (Coneval, 2014).

\section{Una mirada a lo micro: Michoacán}

Con base en el recorrido que se ha hecho respecto del condicionante económico-político del país y su repercusión en diferentes ámbitos estructurales, toca el turno mirar a lo cercano. Con ello no se quiere descartar este marco contextual que afecta en mayor o menor medida a todos los actores sociales que se instauran en el ambiente mexicano; lo que se pretende, en todo caso, es tener una mirada particular de cómo lo macro influye en lo micro, y para esto se hará una vinculación del panorama que enfrenta Michoacán respecto a 
la estructura familiar y las formas de comunicación entre padres e hijos y su impacto en el desarrollo académico.

La familia se toma como referente, ya que es sin lugar a dudas la unidad básica del sistema social y el primer contexto socializador a partir del cual se producen los aprendizajes básicos a través del establecimiento de vínculos entre sus miembros, de pautas de conducta, y la entrega de elementos cognitivos, emocionales, físicos que dotarán al individuo de actitudes y habilidades para enfrentarse el mundo social (Sarto, 2003, citado en Rivadeneira, 2013).

Por tanto, el valor que tiene la familia en el contexto social es apremiante. Esto es así porque es el núcleo de la sociedad y porque es en ella donde se forman los hombres y mujeres que mediante sus decisiones hacen de este mundo un entorno mejor.

\section{Familia, comunicación y desarrollo académico en Michoacán}

Michoacán es un estado lleno de contrastes, ya que por un lado se caracteriza por sus bellos paisajes, por su producción artístico-cultural y por ocupar los primeros lugares a nivel nacional en la producción de guayaba, aguacate, limón, mango y zarzamora, entre otros. Sin embargo, es también una de las regiones del país que presentan severas problemáticas de índole social, económico y político, entre las que destaca el deficiente desarrollo educativo.

Cabe resaltar que la situación en la que se encuentra el estado no sólo es producto de la política gubernamental actual; detrás de este escenario hay todo un complejo trasfondo de hechos históricos que lo han marcado y que sin duda han definido su rumbo. El territorio michoacano estuvo habitado por otomíes, matlazincas o pirindas y tecos. Sin embargo, fueron los nahuas y los purépechas quienes predominaron, siendo estos últimos quienes impidieron la conquista del territorio tarasco por parte de los aztecas.

En la época colonial, Michoacán formó parte del llamado Reino de México, el cual fue repartido en encomiendas a los españoles que participaron en su conquista; las poblaciones más importantes se consideraron Alcaldías Mayores y, al constituirse en provincia, abarcó parte de los límites del imperio Tarasco (Inafed, s.f.). En este lapso diversas órdenes religiosas como la de San Francisco, la de los agustinos, los carmelitas, los jesuitas y los mercedarios se encargaron de evangelizar a los nativos y establecieron sus conventos a lo largo de la provincia.

Durante todo el período colonial, la economía estuvo concentrada en manos de los españoles, quienes acapararon grandes extensiones de tierras, dando origen a innumerables haciendas, 
así como a la explotación de los minerales en importantes poblaciones, como Tlalpujahua, Angangueo y Huetamo.

Los españoles, a través de diversos mecanismos legales tales como las encomiendas, repartimientos y trabajos forzosos, explotaron la fuerza de trabajo de los indígenas y de las diversas castas y esclavos, que se generaron en el proceso de mestizaje y colonización.

La educación estuvo restringida fundamentalmente para los españoles y sus descendientes directos y era manejada por el clero, el cual se constituyó en una clase social poderosa (Inafed, s. f., párr. 12, 13 y 14).

En la Independencia, Michoacán, antes Valladolid, fue el lugar donde se realizó la primera conspiración, esto debido al hartazgo que existía por parte de la sociedad ante los abusos de los españoles y derivado del hecho de que en el Colegio de San Nicolás y en el Seminario Tridentino de San Pedro y San Pablo se prepararon los caudillos y dirigentes insurgentes que iniciaron el movimiento por la independencia desde mediados del siglo XVIII, donde se comienzan a dejar sentir las ideas de la Ilustración (Inafed, s. f.). La vida independiente comenzó con la creación del estado de Michoacán al expedirse el Acta Constitutiva de la Federación, el 31 de enero de 1824. Se instaló el Congreso Local Constituyente y en el artículo 5ํ de la Constitución Federal de 1824, Michoacán se incluyó como parte integrante de la Federación, en calidad de estado (Inafed, s. f.).

Si bien el fragmento histórico que se plasmó en este trabajo es insuficiente, da cuenta de la complejidad de la situación en Michoacán e ilustra el contexto que deviene de un pasado lleno de contradicciones y de luchas entre fuerzas/poderes. Como se puede apreciar, ya desde entonces existían los abusos, gracias a los cuales se fue incrementado la pobreza y la desigualdad social que hoy impera. Alrededor de 1907, por ejemplo, se dio la entrada de compañías y capitales extranjeros, que explotaron de manera irracional los productos naturales del estado y del país, principalmente materias primas de exportación, como minerales y maderas. Además, hubo despojos de tierras a los campesinos y se inició su concentración paulatina en manos de los hacendados (Inafed, s. f.).

Tras este recuento muy resumido de hechos, la misma historia hace patente la riqueza con que cuenta el estado y deja constancia al mismo tiempo de sus desigualdades. Específicamente, el tema de la educación y su desarrollo deficiente es prioritario, ya que de 2009 a 2013 el estado se colocó en los últimos lugares de desempeño educativo en lo concerniente a las dimensiones de permanencia, profesionalización docente, supervisión y participación en las escuelas (Mexicanos Primero, 2014). En cuanto a los resultados del Programme for International Student Assessment (PISA) en 2009, 54.1\% de los estudiantes se encontró 
en los niveles bajos en cuanto a matemáticas y sólo 2.5\% en niveles altos. En comprensión lectora de ese mismo año, $44.3 \%$ se ubicó en niveles bajos, mientras que sólo 3\% en niveles altos (INEE, 2010). En lo referente al 2012, los resultados de la prueba PISA no fueron significativos y no se consideran en los informes porque la tasa de participación fue inferior a 65\%, ya que sólo cooperaron 31 escuelas de todo el estado (SEP, 2013). Por último, de acuerdo con los resultados del censo del Instituto Nacional de Estadística y Geografía (Inegi) del 2010, Michoacán ocupó el lugar treinta debido a que el grado promedio de escolaridad de la población de 15 años y más fue de $7.4 \%$, lo que equivale a poco más de primer año de secundaria (Inegi, 2011).

Si bien es cierto que los problemas en la educación son multicausales e involucran a múltiples actores, la comunicación es el principal factor que frena el desarrollo educativo al ser el medio por el cual se transmiten principios de conducta, valores, habilidades, actitudes ante la vida y conocimientos disciplinares. La comunicación es en sí misma la que hace a los individuos y a la par son los individuos quienes hacen la comunicación, de tal suerte que al haber deficiencias en el proceso evidentemente los resultados en términos educativos no serán los esperados, puesto que la interacción entre los padres, hijos y profesores (escuela) es prioritaria para el desarrollo óptimo de los individuos en el ámbito académico.

La responsabilidad de educar es una tarea compartida: padres y escuela son las principales instancias; no obstante, el mayor peso sigue estando en el seno familiar, puesto que los padres, como primera fuente de socialización, enseñan a los hijos determinadas formas de comunicarse mediante las cuales se producen interacciones comunicativas que determinan cómo los miembros de la familia experimentan la realidad y la construyen. Las relaciones familiares son las que primero ocurren en la vida de un individuo y son en gran medida un modelo de comportamiento social.

La familia es la que puede promover el desarrollo personal y social de los niños, donde los padres ponen en juego ciertos estilos o prácticas de crianza que determinan el tipo de relación padre-hijo y los niveles de desarrollo psicológico en diversas habilidades y competencias (Jiménez, 2009).

En este sentido se observa que, debido a las condiciones socioeconómicas de Michoacán, donde $80 \%$ de la población se encuentra clasificada como pobre y en pobreza extrema, según los ingresos por hogar (Millán, 2013) así como por el bajo nivel de desarrollo humano (0.700), que lo ubica en 2012 en el lugar treinta a nivel nacional (Morelia Global, 2015), también derivado de la forma de vida imperante en el siglo XXI, caracterizada por la inmediatez, la rapidez, el consumo y la aspiración a una mejor forma de vida, el involucramiento parental en la educación de los hijos ha disminuido o no existe. 
Hoy en día es común que tanto el padre como la madre trabajen; esto ha ocasionado que se disponga de menos tiempo para pasar con los hijos y, por ende, para estar al tanto de lo que sucede en su ámbito académico. De acuerdo con información del Inegi, en 2015 había, en el último trimestre de ese año, 162,065 hombres y 133,658 mujeres ocupados laboralmente, lo cual puede explicar que se pase menos tiempo en casa con los hijos, así como el hecho de que la mujer se encuentra más tiempo fuera del hogar y, por tanto, alejada de los hijos.

A lo anterior se suman los indicadores de bienestar asociados al balance vida-trabajo en los rubros "empleados trabajando más de 48 hrs. semanales" y "satisfacción con tiempo para ocio". Los resultados de este estudio realizado por la OCDE, con base en datos estadísticos del Inegi (2014), señalan que en Michoacán la percepción de la población ocupada que trabaja más de 48 horas por semana es de $21.36 \%$, lo cual coloca al estado en el lugar treinta y uno a nivel nacional, que no resulta negativo. Sin embargo, al contrastarlo con la satisfacción de tiempo para el ocio en 2014, en una escala que va del 0 al 10, sólo $7.5 \%$ está a favor del criterio que lo coloca en el nivel 10 (Inegi, 2014), lo cual lleva a la reflexión de que las personas ocupadas laboralmente en general no disponen de tiempo suficiente para el ocio, para estar en familia, pese a que un porcentaje menor es el que dice laborar más de 48 horas semanales.

La situación económica de muchos hogares en el estado ha influido en elloy la necesidad de obtener mayores recursos en aras de garantizar un mejor nivel de vida ha demeritado la calidad de las relaciones comunicativas en el seno familiar y ha causado, también, una redefinición de roles al interior de la familia debido a la incorporación de la mujer al mundo laboral, ya sea como jefa de familia (ver Tabla 1) o simplemente como un apoyo. En tanto, el hombre ha tenido que migrar a Estado Unidos para enviar recursos económicos:

La emigración michoacana ha construido, de manera silenciosa y paulatina, una cultura propia que se expresa en costumbres y práctica sociales, algunas positivas y otras no tanto, por ejemplo: la existencia de pueblos vacíos de hombres; los rompimientos de familias; la dependencia de las remesas que, si bien mitigan la pobreza, generan dependencias que inhiben la búsqueda de alternativas; la reinserción, en ocasiones traumática, de los que son deportados después de vivir largos periodos en Estados Unidos (Mohar, s. f. citado en Entre hombres, 2013).

Ante este hecho, la mujer se ha quedado sola a cargo del hogar o ha acompañado a su pareja, dejando a los hijos al cuidado de familiares cercanos. La migración provoca un cambio en la estructura familiar: las mujeres se convierten en cabeza de familia y comienzan a ejercer roles que antes no tenían, y estos roles conllevan más responsabilidades. Los núcleos familiares cambian cuando los padres varones forman una familia en Estados Unidos (Mercado \& Palmerín, 2009). 
TABLA 1. DISTRIBUCOÓN DE LASJEATURAS FAMILARES EN MICHOACÁN DE ACUERDO CON I G GÉNERO

\begin{tabular}{|l|c|}
\hline Hogares totales & $31,689,178$ \\
\hline Hogares con jefaturas masculinas & $23,670,239$ \\
\hline Hogares con jefaturas femeninas & $8,018,940$ \\
\hline
\end{tabular}

FUENTE: FORMULACIÓN PROPIA A PARIR DE DATOS DE CONAPO 2014.

En cuanto a la jefatura femenina, ésta aumentó 3.8 puntos porcentuales entre 2010 y 2015. Actualmente una mujer está al frente de 27.9 por ciento de los hogares (Redacción Quadratín, 2015).

Respecto a la migración a Estados Unidos por la falta de oportunidades laborales, baste decir que Michoacán ocupó el tercer lugar nacional en 2010 (González, 2015). Así también, en ese mismo año, dentro de los municipios con mayores índices absolutos de intensidad migratoria (IAIM) se encontraban dos pertenecientes al estado: Morelos y Chucándiro (Conapo, 2014). Por otro lado, en 2014, Michoacán ocupó el primer lugar de la lista en cuanto a los ingresos por remesas con 2,229.7 millones de dólares. Aunque en tasa de crecimiento anual de los ingresos por remesas de entre 2012 y 2013 se colocó en el lugar veintiuno a nivel nacional con $9.2 \%$ (IME, 2016).

Como se observa, las desigualdades en la distribución del ingreso promueven activamente la migración. Las remesas, al incidir en el consumo y el ahorro familiares, tienen efectos redistributivos en el corto y largo plazo. Financian gastos de consumo e inversión familiar, lo que no se podría con ingresos obtenidos únicamente en México (Santiago Cruz \& Barrios Puente, 2000, citados por Tapia, 2007). Sin embargo, en los últimos años éstas han descendido para Michoacán; por ejemplo, durante el primer trimestre del año 2013 y con relación a 2012, las remesas fueron negativas en $9 \%$, esto con base en datos arrojados por el Banco Mundial (Orozco, 2013). En este sentido, el impacto que causa la migración de michoacanos a EE. UU. desde el punto de vista económico es fundamental para el desarrollo de Michoacán, ya que la economía del estado y de muchas de sus familias depende de este envío de remesas para su subsistencia. Por tanto, "la disminución de las remesas puede desencadenar problemas graves sumados a los que actualmente existen en el estado como lo son el crimen organizado, inestabilidad política y social, ya que las remesas son hoy en día uno de los pilares primordiales de ingreso en el estado" (Orozco, 2013) y ello desde luego influirá en la conformación de los roles al interior de las familias, en aspectos de educación, 
en asuntos relativos al nivel cultural de la sociedad michoacana y en la conformación de cierto tipo de creencias o imaginarios.

En algunos hogares se mantiene la idea de que la educación y la obtención de conocimientos científicos o enfocados al fortalecimiento de habilidades o destrezas cognitivas es tarea exclusiva de la escuela, con lo que el vínculo entre padres y actividades escolares (tareas, trabajos, ejercicios, etc.) es nulo, o bien, se reduce a la asistencia a reuniones para entrega de calificaciones. La participación de los padres es limitada, pues incluye sólo su asistencia a reuniones formales $\mathrm{u}$ otras actividades y da poca importancia a las reuniones que se establecen en casa entre padres e hijos (Moreno, 2010).

En un estudio realizado por Ishihara (2008) se puede observar que una madre comentó que uno aprende cosas malas sólo en la calle y no en la escuela ni en la casa; es decir que, si no se está en la escuela, se aprenden cosas malas. Este comentario permite asociar que lo que muchos padres consideran como educación se circunscribe al ámbito escolar. En este mismo trabajo se muestran algunas de las razones por las cuales los padres envían a sus hijos a la escuela: para que estudien, para que aprendan, para que aprendan a leer y escribir; porque la educación es lo más importante y porque la educación es para el bien de los niños en la medida en que va a mejorar su vida cuando sean grandes (Ishihara, 2008).

Este hecho favorece que el desarrollo académico de los hijos, sobre todo en el nivel básico (primaria), sea deficiente. En Michoacán, por ejemplo, los resultados globales de 2006, 2007, 2009, 2010, 2011, 2012 y 2013 de la Evaluación Nacional del Logro Académico en Centros Escolares (ENLACE) demuestran que, si bien ha habido un decremento en los porcentajes de insuficiente y elemental en las áreas de español y matemáticas, aún hay mucho por hacer, ya que al 2013 únicamente 13.3\% de los alumnos se encontraba en la categoría de excelencia en español, mientras que sólo $27.6 \%$ en lo concerniente a matemáticas (SEP, 2014).

Pocos padres tienen conciencia de que la base de un desarrollo académico óptimo está en la infancia, en los primeros grados escolares; algunos conciben que son más importantes para el individuo los niveles educativos superiores, en la medida en que de ellos depende el desarrollo profesional y la obtención de una fuente de ingresos. Así, se evade la responsabilidad de apoyar la superación intelectual de los hijos por medio de la interacción comunicativa en el seguimiento de la trayectoria escolar para formar individuos plenos, capaces de desenvolverse en contextos diversos, con habilidades para "comunicarse de una manera eficiente, trabajar en equipo, resolver problemas, usar efectivamente las tecnologías de la información para adoptar procesos y tecnologías superiores, así como para comprender el entorno en el que vivimos y poder innovar" (Gobierno de la República, 2013, p. 16).

Con base en lo anterior, son pocas las familias en las que se genera un ambiente estimulador de los procesos de pensamiento mediante un diálogo abierto, sincero y participativo 
entre padres e hijos. No existen los incentivos suficientes para que los niños desarrollen satisfactoriamente las habilidades de lectoescritura, las habilidades creativas, las intelectuales y las críticas por parte de los progenitores. Tampoco se generan espacios que beneficien la confianza y seguridad de los pequeños, puesto que no se les atribuye la madurez suficiente para tomar decisiones que refuercen su personalidad.

El valor del estudio como mecanismo de crecimiento personal y social es menospreciado. Los hábitos de estudio poco se toman en cuenta como base para el mejor desempeño escolar de los hijos. Una de las principales causas de los altos índices de fracaso académico en México es el inadecuado desarrollo de los hábitos de estudio desde el nivel educativo básico (Tinto, 1998, citado por Díaz, García \& León, 2003).

Finalmente, hay que destacar también que parte del problema lo conforma el mismo nivel educativo de los padres, ya que, de acuerdo con resultados del Inegi en 2010, en Michoacán de cada 100 personas de 15 años y más 61.8\% tenía la educación básica terminada, 14.8\% la educación media superior y 11.8\% la educación superior (Inegi, 2011). Lo anterior se traduce en la incapacidad de los padres para ayudar a los hijos en las tareas escolares, pues tienen sesgos en cuanto a conocimiento se refiere y por ende no cuentan con las competencias necesarias para fortalecer el desarrollo académico de los niños. Esto puede verse también como una deficiencia en el proceso comunicativo, ya que genera ruidos semánticos debido a la disparidad entre los códigos que se utilizan en la escuela y en el seno familiar. Hay padres que se percatan de que deben apoyar a los hijos, pero les es imposible hacerlo por falta de tiempo y de cultura (Avanzini, 1969, citado en Valdés, Martín \& Sánchez, 2009).

\section{Vinculación de elementos coyunturales y el contexto específico michoacano}

Se partió de la noción de liberalismo y neoliberalismo para explicar su incidencia en la situación coyuntural en que se encuentra México actualmente. El panorama desde el punto de vista económico no resulta alentador, y menos cuando hay evidencias de que el crecimiento y desarrollo económico-social es lejano. No obstante, la importancia de analizar la situación en toda su complejidad puede dar luz para plantear alternativas de solución.

En este caso se puede ver cómo la política neoliberal afecta en gran escala, pero también en pequeña escala a la sociedad. La familia en el contexto michoacano se ha visto mermada por la situación económica desfavorable, incluso ha tenido que cambiar su misma estructura por el hecho de aspirar a una mejor calidad de vida. 
Como se observa en las evidencias, cada vez es más frecuente que las mujeres ingresen al ámbito laboral y que sean jefas de familia, lo cual hace que se vean afectadas las relaciones comunicativas entre padres e hijos. Los hombres, por su lado, han tenido que emigrar a EE. UU. (en ocasiones también las mujeres); no es gratuito que Michoacán ocupe en esto los primeros lugares, pues existe una asociación muy fuerte entre las carencias económicas y educativas y la falta de oportunidades laborales bien remuneradas.

Tanto a nivel macro como a nivel micro se viven condicionantes semejantes. Finalmente, Michoacán se encuentra circunscrito en un contexto más amplio que, sibien no determina el desarrollo económico-social, sí lo influye. Los tratados aplican para el estado, las dinámicas laborales asimétricas para migrantes permanecen vigentes; la pérdida de poder adquisitivo igual se padece; la penetración de corporaciones globales se evidencia a través de las grandes cadenas de supermercados (Walmart, por ejemplo), que han llevado a la quiebra a microempresas, o en el sector minero (Calissio Resources Group Inc. o Amarium Mineral Inc. Subsidiary of Amarium Technologies Inc., ambas de procedencia estadounidense).

El resultado es que las oportunidades de crecimiento han descendido; la brecha entre los que tienen y no tienen se ha acentuado; la pobreza se ha incrementado; los niveles educativos han colapsado, y la comunicación familiar se vuelve cada vez menos frecuente, de menor calidad o prácticamente inaccesible.

La pregunta es ¿qué se puede hacer?, ¿cómo salir de esta situación?, ¿existen alternativas de solución? Y la respuesta, por supuesto, no es sencilla. Sin embargo, a continuación se retoma un planteamiento que pudiera responder a la necesidad de volver a una vida menos interesada en lo económico y más atenta a la justicia, la solidaridad, la equidad y la libertad.

La propuesta a que se hace referencia es la de generar una comunidad nacional, la cual se retoma del Centro de Estudios Estratégicos Nacionales, A. C. (CEEN), que presenta la idea de que las finalidades del quehacer humano se circunscriban a ciertos valores universales con base en los cuales se garantice una realización plena, pero sobre todo un crecimiento económico en el que las personas sean fines en sí mismos y no medios u objetos.

Entonces, lo primero que se debe hacer para ver a los otros como fines intrínsecos es reformular las condiciones en que el sujeto social interactúa. El fundamento deberá estar asociado a valores o principios universales, tal y como lo acota la filosofía práctica, ya que sólo en esta medida se podrá asegurar una aplicación más amplia. Sin embargo, no se deben olvidar las particularidades de los hechos concretos (medios), es decir, las características propias, especiales y singulares de cada sujeto u objeto para que, en la praxis y con el hábito, se desarrollen seres humanos virtuosos y, por ende, sociedades éticas.

Desde luego un tipo de organización así requiere que desde la familia se inculquen dichos valores universales; por ello es vital reconsiderar la importancia de la familia como 
mecanismo de crecimiento y desarrollo colectivo, ya que es dentro de ésta donde se inician los primeros intercambios sociales, donde se adquieren patrones de conducta y se transmiten los valores éticos que una sociedad democrática requiere.

Con base en la propuesta del CEEN (2010), el fin del desarrollo nacional o de la comunidad ética sería la humanización de todas las personas, cuyos marcos de referencia universales estarían integrados por la libertad, la soberanía y la justicia social por considerarse fines en sí mismos. Mientras que los medios estarían conformados por la educación integral, la gobernabilidad democrática y el crecimiento económico (Montoya et al., 2010).

En cuanto a la educación integral, ésta se vinculará directamente con la libertad, entendida esta última como la facultad o disposición de autodeterminación de las personas. Su nexo es estrecho dado que mediante la educación se dinamiza la conciencia, la realización y la autoafirmación de los individuos en la toma de decisiones en la sociedad (Montoya $e t$ al., 2010). Si se cuenta con más información y con mayores experiencias significativas, el conocimiento (capital humano) podrá entonces incrementarse y ello representará mayores posibilidades de desarrollo económico y social que se reflejarán en el nivel de vida de un país. Al respecto, "el límite de civilización de un pueblo está en su educación" (Montoya et al., 2010, p. 8).

La gobernabilidad democrática se relaciona con la justicia social, dado que para que exista la primera se debe concebir a los otros como semejantes y en esa medida valorar el esfuerzo y capacidad de cada uno, esto significa que se debe reconocer y respetar ante todo la dignidad humana y en función de ello promover la igualdad de oportunidades. Si bien en una sociedad existen las diferencias, éstas son las que enriquecen y, sin enfatizarlas, se debe garantizar que sean respetadas y valoradas. El gobierno democrático en consecuencia será aquél que no pierda de vista la justicia social y que por el contrario haga valer el derecho de los ciudadanos para exigir cuentas, por un lado, y por otro, que garantice una vida organizada, transparente, responsable y eficaz a través de la promoción de prácticas democráticas que fomenten la participación de los ciudadanos en la toma de decisiones del país.

Por último, respecto al crecimiento económico, su nexo directo se puede establecer con la soberanía, dado que esta autodeterminación del Estado siempre debe corresponder a las necesidades y voluntad de la sociedad a la que se debe; jamás se debe permitir la violación a la misma en aras de mejoras de tipo económico. Como lo señalan Montoya et al. (2010) "la autodeterminación de un Estado nación y la legitimidad de la globalización sólo se justifican en la medida que promueven de manera concreta la realización de toda persona en su ámbito nacional e internacional” (p. 7).

Medios y fines, fines y medios deberán estar vinculados estrechamente, ya sea de manera global, o específica, deben tener congruencia entre sí. La falta de conectividad entre ellos 
podría desencadenar desequilibrios sociales, económicos y políticos, los cuales justamente ahora se presencian. Si bien en el ejercicio que se hizo se trató de relacionar cada fin con un medio en particular, se puede inferir que la libertad, por ejemplo, no sólo se garantiza o fomenta a través de la educación, también influyen la gobernabilidad y el crecimiento económico. En cuanto al resto de los medios (fines), soberanía y justicia social, la situación es similar. Finalmente, también prevalece una interdependencia entre los valores mismos, uno sin el otro no podría concebirse.

De esta manera, el análisis económico debería centrarse en cómo ocurren los procesos de innovación y aprendizaje para en función de ello revisar las formas de intervención del gobierno, ya que éste tiene un papel central al moldear una economía innovadora y promover el aprendizaje. Por tanto, "crear una sociedad del aprendizaje debería ser uno de los principales objetivos de la política económica” (Stiglitz \& Greenwald, 2014, p. 26).

\section{Conclusiones}

México tiene múltiples retos que vencer. Sin embargo, uno de los más fuertes es la inestabilidad económica que se avecina y que de hecho ya se comienza a percibir en el alza del dólar. Si bien es cierto que se requieren estrategias a corto plazo para revertir esta situación (si es que es posible) o en su defecto para aminorarla, también es indispensable que cambie la orientación de las políticas nacionales en términos de tratados y acuerdos y que se considere tanto el mediano como el largo plazo a partir de factores internos, para así evitar el exceso de dependencia hacia los factores extrínsecos o externos sobre los cuales poco o nada se puede hacer.

Si se piensa que es difícil cambiar el entorno internacional de manera dramática en los próximos años resultan importantes las fuentes internas de crecimiento, ya que de éstas dependerá un mayor desarrollo y el abatimiento de los niveles de pobreza del país.

El objetivo de los gobernantes en este contexto global, debería ser la búsqueda del bien común, el beneficio para todos y la justicia social en cuanto al acceso de oportunidades. Lastimosamente, para llegar a esto se requiere un cambio en la mentalidad de las personas, en quienes dirigen y quienes gobiernan, pero también en quienes en apariencia no tienen ningún poder, ya que en la sociedad civil permanece latente la posibilidad de crecimiento.El país necesita una conducción hacia una sociedad del aprendizaje y la revaloración del capital humano que tome como base la familia y la comunicación que se da entre sus miembros.

Para concluir, en Michoacán, específicamente, se requieren estudios formales en los que se pueda observar de manera detallada, a través de la etnografía, entrevistas a profundidad 
e incluso encuestas, la forma en que los aspectos macroeconómicos y políticos del país inciden de manera poco positiva en las relaciones interpersonales familiares; así como en los cambios estructurales que se han observado en la familia y su relación con el desarrollo académico de los niños, todo ello teniendo como eje el proceso de comunicación.

\section{Referencias}

Anónimo (21 de febrero de 2016). Hacienda destaca acciones coordinadas para preservar estabilidad. Excélsior. Recuperado de http://www.excelsior.com.mx/nacional/2016/02/21/1076510

Bobbio, N. \& Matteucci, N. (1982). Diccionario de política. México: Siglo XXI.

Committee on Foreign Relations (2012). Oil, Mexico and the transboundary agreement. A minority staff report prepared for the use of the committee on foreign relations, United States Senate, One hundred twelfth Congress, second session. Recuperado de http://www.gpo.gov/fdsys.

Conapo (2014). Índice absoluto de intensidad migratoria México-Estados Unidos 2000-2010. Recuperado de http://omi.gob.mx/work/models/OMI/Resource/1770/1/images/Inice_absoluto_intensidad_migratoria_Mex_EU_2000_2010.pdf.

Coneval (2014). Informe de Evaluación de la Política de Desarrollo Social 2014. Recuperado de http://www.coneval.gob.mx/Evaluacion/Paginas/IEPDS_2014.aspx.

Council on Foreign Relations, Canadian Council of Chief Executives, Consejo Mexicano de Asuntos Internacionales (2005). Building a North American Community. Report of the Independent Task Force on the Future of North America. Nueva York, United States of America.

Díaz, M., García, E. \& León, A. (2003). Diagnóstico de bábitos de estudio en alumnos de primer ingreso al nivel superior de UAE Méx. Recuperado de http://148.213.1.36/Documentos/Encuentro/ $\mathrm{PDF} / 10$. pdf.

IME (2016). Ingresos por remesas por entidad federativa 2014. Reporte de remesas cifras al cierre de 2014. Recuperado de http://www.ime.gob.mx/es/remesas.

Inafed (s. f.). Michoacán de Ocampo. Enciclopedia de los municipios y delegaciones de México. Recuperado de http://www.inafed.gob.mx/work/enciclopedia/EMM16michoacan/historia.html

Ferguson, J. (1980). Historia de la economía. México: FCE.

Forbes México (2015). Banxico recorta previsión del PIB: entre 1.7 y 2.5 para 205. Recuperado de http://www.forbes.com.mx/banxico-recorta-intervalo-de-crecimiento-para-2015-preve-entre- 1-7-y-2-5.

Gobierno de la República (2013). Plan Nacional de Desarrollo 2013-2018. Recuperado de http:// pnd.gob.mx/wp-content/uploads/2013/05/PND.pdf.

González, A. (9 de agosto de 2015). Michoacán, riqueza y miseria. La Voz de Michoacán. Recuperado de http://www.lavozdemichoacan.com.mx/michoacan-riqueza-y-miseria.

Huerta, J. (2014). Liberalismo. Liberalismo.org. Recuperado de http://www.liberalismo.org. 
INEE (2010). México en PISA 2009. Recuperado de https://www.sep.gob.mx/work/models/sep1/ Resource/1073/1/images/V5\%200-PISA-INEE-07DIC2010numA.pdf.

Inegi (2011). Cuéntame, información por entidad. Recuperado de http://www.cuentame.inegi.org. $\mathrm{mx} / \mathrm{monografias} /$ informacion/mich/poblacion/educacion.aspx?tema=me\&e $=16$

Inegi (2014). Indicadores de bienestar por entidad federativa. Recuperado de http://www.beta. inegi.org.mx/app/bienestar/?ag=16.

Inegi (2014). Estadísticas sobre disponibilidad y uso de tecnologías de la información y comunicaciones en los hogares, 2013. Recuperado de http://www.inegi.org.mx/prod_serv/contenidos/espanol/bvinegi/productos/metodologias/MODUTIH/MODUTIH2013/MODUTIH2013.pdf.

Jiménez, D. (2009). Estilos de crianza y su relación con el rendimiento académico: análisis y propuestas de intervención (Tesis de doctorado). México: UNAM.

Ishihara, R. (2008). La calidad es la oportunidad: percepciones de los padres y las madres sobre la calidad educativa que reciben sus bijos e bijas. Recuperado de https://www.academia.edu/1488385/ La_Calidad_es_la_Oportunidad_Percepciones_de_los_Padres_y_Madres_sobre_la_Calidad_Educativa_que_Reciben_sus_Hijos_e_Hijas.

Justo, M. (2015). Las 10 ciudades del mundo que tienen mayor crecimiento económico. BBC Mundo. Recuperado de http://www.bbc.com/mundo/noticias/2015/02/150212_economia_ciudades_crecimiento_mj.

Mercado, H. \& Palmerín, M. (2009). Causas y consecuencias de la migración de mexicanos a los Estados Unidos de América. Recuperado de http://www.eumed.net/libros-gratis/2009c/597/REMESAS\%20Y\%20SU\%20IMPORTANCIA\%20EN\%20EL\%20ESTADO.htm

Mexicanos Primero (2014). Índice de Desempeño Educativo Incluyente. Recuperado de http:// www.mexicanosprimero.org/index.php/educacion-en-mexico/como-esta-la-educacion/ idei-indice-de-desempeno-educativo-incluyente/idei-2009-2013.

Entre Hombres (2013). Michoacán, Migración. Recuperado de http://www.entrehombres.net/67-michoacan-migracion.

Millán, M. (2013). Análisis de factores socioeconómicos para el mejoramiento de la infraestructura carretera federal como factor de desarrollo: caso Michoacán 2011-2012 (Tesis). Universidad Autónoma del Estado de México. Recuperado de http://ri.uaemex.mx/bitstream/123456789/21782/1/ MILLAN-MICHAEL-LGE-2013.pdf.

Montoya, A. (2015). Estrategia de reindustrialización acelerada de México. México: Senado de la República/Centro de Estudios Estratégicos Nacionales/Editorial Limusa.

Montoya, A. (2014). Análisis del II informe entregado al congreso de la unión por Enrique Peña Nieto, presidente constitucional de los Estados Unidos Mexicanos, en materia de política exterior: comparecencia ante el $\mathrm{H}$. Senado de la República del secretario de relaciones exteriores José Antonio Meade Kuribreña. México: Mimeo.

Montoya, A., Olvera, J., Brito, L. \& Lara, H. (2000). Metodología del pensamiento estratégico nacional. México 2010: pensar y decidir la próxima década (pp. 65-103). México: CEEN/UAM Grupo Editorial Noriega. 
Morelia Global (2015). Índice de Desarrollo Humano para las entidades federativas, México 2015 del PNUD. Recuperado de http://moreliaglobal.com/indice-de-desarrollo-humano-pnud.

Moreno, T. (2010). La relación familia-escuela en secundaria: algunas razones del fracaso escolar. Profesorado: revista de currículum y formación del profesorado, 14 (2), 241-255. Recuperado de http://www.ugr.es/ recfpro/rev142COL3.pdf.

Nusbaum, M. (2014). Una revisión del liberalismo político de Rawls. Revista Derecho del Estado, 32 , 5-33. Recuperado de http://revistas.uexternado.edu.co/index.php/derest/issue/view/384.

Orozco, E. (2013). ¿Remesas a la baja en el estado de Michoacán? CIMEXUS, 8 (1), 49-63. Recuperado de http://cimexus.umich.mx/index.php/cim1/article/view/79/72.

Petraeus, D., Zoellick, R. \& Shannon, K. (2014). North America. Time for a Nerw Focus. Independent Task Force Report, No. 71. Council on Foreign Relations, New York, N.Y. United States of America. Recuperado de www.cfr.org.

Redacción Quadratín (16 de diciembre de 2015). Aumentan hogares con jefatura femenina en Michoacán. Quadratín. Recuperado de https://www.quadratin.com.mx/sucesos/Aumentan-hogares-jefatura-femenina-Michoacan.

Rionda, J. I. (s. f.). El ocaso del neoliberalismo en México (síntomas, supervivencias y renacimientos). Eumed. Recuperado de http://www.eumed.net/libros-gratis/2011c/1011/LIBERALISMO\%20Y\%20MODERNIDAD\%20EN\%20MEXICO.htm

Romero, M. (2015). Neoliberalismo: la fosa de México. Contralínea. http://www.contralinea.com. $\mathrm{mx} /$ archivo-revista/index.php/2015/01/11/neoliberalismo-la-fosa-de-mexico.

Salbuchi, A. (2003). El Council on Foreign Relations (CFR): la cara oculta del poder globalizado. Mimeo. Buenos Aires.

Secretaría de Educación Pública (2014). ENLACE 2014. Recuperado de http://www.enlace.sep. gob.mx/content/ba/pages/estadisticas/estadisticas_2013.html.

Secretaría de Economía (2016). Seguimiento precio del petróleo mezcla mexicana (MME). Recuperado de http://portalweb.sgm.gob.mx/economia/es/energeticos.html.

Stiglitz, J. (2007). El consenso post-consenso de Washington. The initiative for policy dialogue. Estados Unidos: Universidad de Columbia.

Stiglitz, J. \& Greenwald, B. (2014). La creación de una sociedad del aprendizaje. México: Crítica.

Tapia, E. (2007). Migración y remesas en Michoacán: Discursos y realidades. CIMEXUS, 2 (1), 67-82. Recuperado de http://cimexus.umich.mx/index.php/cim1/article/view/25/22.

Valdés, A., Martín, M. \& Sánchez, P. (2009). Participación de padres de alumnos de primaria en las actividades académicas de sus hijos. Revista electrónica de investigación educativa, 11 (1), 1-17. Recuperado de http://www.redalyc.org/articulo.oa?id=15511137012. 